\title{
Effects of age, gender and menstrual cycle on platelet function assessed by impedance aggregometry
}

Gösta Berlin, Mats Hammar, L. Tapper and Nahreen Tynngård

The self-archived postprint version of this journal article is available at Linköping University Institutional Repository (DiVA):

http://urn.kb.se/resolve?urn=urn:nbn:se:liu:diva-156901

N.B.: When citing this work, cite the original publication.

This is an electronic version of an article published in:

Berlin, G., Hammar, M., Tapper, L., Tynngård, N., (2019), Effects of age, gender and menstrual cycle on platelet function assessed by impedance aggregometry, Platelets, 30(4), 473-479.

https://doi.org/10.1080/09537104.2018.1466387

Original publication available at:

https://doi.org/10.1080/09537104.2018.1466387

Copyright: Taylor \& Francis (STM, Behavioural Science and Public Health Titles)

http://www.tandf.co.uk/journals/default.asp 


\title{
Effects of age, gender and menstrual cycle on platelet function assessed by impedance aggregometry
}

\author{
Berlin $\mathrm{G}^{1}$, Hammar $\mathrm{M}^{2}$, Tapper $\mathrm{L}^{1}$, Tynngård $\mathrm{N}^{3}$ \\ ${ }^{1}$ Department of Clinical Immunology and Transfusion Medicine, and Department of Clinical \\ and Experimental Medicine, Linköping University, Linköping, Sweden \\ ${ }^{2}$ Department of Obstetrics and Gynaecology, and Department of Clinical and Experimental \\ Medicine, Linköping University, Linköping, Sweden \\ ${ }^{3}$ Research and Development Unit in Region Östergötland and Department of Medical and \\ Health Sciences, Linköping University, Linköping, Sweden
}

Corresponding author: Nahreen Tynngård; PhD

Research and Development Unit in Region Östergötland.

S:t Larsgatan 9D, 58185 Linköping, Sweden,

Tel: +46 (0)10-1039773

Fax: $+46(0) 10-1038501$

E-mail: nahreen.tynngard@regionostergotland.se

Running head: Effects of age and gender on platelet function

Keywords: Platelet function, aggregation, age, gender, menstrual cycle 


\begin{abstract}
Platelets are needed to prevent or arrest bleeding and aggregate at the site of injury upon vascular damage. Platelets express receptors for estrogens which might affect the function of the platelets and their haemostatic ability. The aim was to identify possible differences in platelet function related to age, gender and phases of the menstrual cycle by use of impedance aggregometry with Multiplate. In the first part of the study platelet function was assessed in 60 healthy individuals (30 men and 30 women) in each of three age groups (20-25, 40-45 and 60-65 years). In the second part of the study the platelet function was analysed on four occasions during the menstrual cycle in women without oral contraceptives $(n=17)$ and compared to 19 women on oral contraceptives (OCs) and 18 men of similar age (20-40 years). For the women on OCs, aggregation was analysed once during the tablet free week and once late during the period with OCs. The men were sampled once. Women of younger age $(<45$ years) had significantly higher agonist induced aggregation response than both men and postmenopausal women (60-65 years). The agonist induced aggregation response did not differ between phases of the menstrual cycle or OC use. The results suggest that estradiol and/or progesterone affect spontaneous aggregation since it was found to be lowest in the mid-luteal phase. Spontaneous aggregation was significantly lower in women on OCs than in both men and women without OCs. Our findings indicate that fertile age is associated with higher aggregation response capacity of the platelets, possibly to prevent excessive bleeding during menstruation, but this response capacity is not altered during the menstrual cycle or by use of OCs.
\end{abstract}




\section{Introduction}

Platelets have an important role in the haemostatic process. Platelets adhere to proteins exposed in the subendothelium resulting in platelet activation, shape change, secretion from intracellular granules, and platelet aggregation which leads to sealing of the damaged vessel. The function of platelets has been shown to be increased during pregnancy [1,2], which could be seen as a preparation for delivery. Estrogens are involved in the sexual and reproductive function of women and their levels vary over the course of the menstrual cycle [3]. Women have much higher levels of estrogens than men but the levels decrease following menopause [4]. Since platelets express receptors for estrogens [5, 6], it is likely that estrogens could affect the function of the platelets as a preparation for delivery but also for menstruation with shedding of the endometrium. It has been shown that estrogens potentiate thrombin-induced platelet aggregation [7]. There might thus be age, gender and menstrual cycle related differences in platelet function.

However, conflicting results have been reported on the effect of age [8-12] and gender [8, 1215] on platelet function. Many of the studies were conducted using light transmission aggregometry (LTA) $[8,9,13,15]$ which is considered to be the gold standard method to assess platelet function. However, this method can only assess platelet function after the platelets have been separated from whole blood and analysed as platelet rich plasma (PRP) or as a washed platelet suspension. This sample preparation might affect the platelets and their function [16].

A newer method, impedance aggregometry, enables analysis of platelet aggregation in whole blood. Impedance aggregometry, using the instrument Multiplate, has gained popularity when monitoring anti-platelet therapy [17]. This method might provide new insight on the effect of 
age and gender on platelet since it makes analysis of whole blood possible without any platelet sample preparation. Sex-related differences in platelet function with Multiplate have been analysed only in a few studies with conflicting results [18-20].

This study investigates the effect of age, gender and changes in the sex-hormones during the menstrual cycle on platelet function using impedance aggregometry (Multiplate). The hypothesis is that platelet activity is higher for women than for men particularly during fertile age and also is higher prior to menstruation than during the rest of the menstrual cycle. 


\section{Methods}

The study was split into two parts. Part 1 aimed at assessing age and sex related differences in platelet function and Part 2 to investigate the effects of changes in sex-hormones on platelet function. The study was approved by the local ethical review board in Linköping, Sweden. All participants received written and/or oral information of the study and gave their oral/written informed consent to participate in the study.

\section{Part 1}

Sixty healthy individuals ( 30 men and 30 women), 20 in each of three age groups of 20-25 years (median age 24 for women, 22 for men), 40-45 (median age 44 for women, 43 for men) and 60-65 (median age of 63 for women, 63 for men) were enrolled in the study based on agreement of participation and fulfilling the inclusion criterion regarding age. Exclusion criterion was intake of pharmaceuticals affecting platelets such as non-steroidal antiinflammatory drugs, acetyl salicylic acid, and platelet receptor antagonists. Blood was collected in a 3.0-mL $\mathrm{K}_{2}$ E Venosafe EDTA tube (Terumo Europe NV, Leuven, Belgium) for analysis of haematology variables and in a 3.0-mL Hirudin tube (Roche Diagnostics GmbH, Mannheim, Germany) for impedance aggregometry.

\section{Part 2}

Seventeen healthy women without oral or other hormonal contraceptives with a median age of 27 years (referred to as test women) were enrolled in the second part of the study to investigate changes in platelet function during the menstrual cycle. To determine the effects of the use of oral contraceptives (OCs), 19 healthy women on combined OCs (i.e. a combination of a synthetic progestogen and also a synthetic estrogen or in some cases estradiol) with a median age of 23 years (referred to as control women) were enrolled in the 
study. To further investigate the effects of sex-related differences on platelet function, 18 healthy men (age 20 - 40 years, median age 30 ) were also included (referred to as control men). The participants were selected based on agreement to participate and fulfilling the inclusion criteria regarding age and use or non-use of OCs. Exclusion criteria were pharmaceuticals affecting platelets and excessive nose or laceration bleeding as well as remarkable bleeding during dental procedures.

The women without OCs (test women) were sampled four times during the menstrual cycle. The first sample was collected during the early follicular phase, at a median of 1 day (range 03 days) from the onset of menstruation. The second was collected at the time of ovulation. To verify that the women were close to ovulation a Clearblue luteinizing hormone (LH) test (SPD, Swiss Precision Diagnostics GmbH, Geneva, Switzerland) was used after the first sample had been collected. When the LH-test indicated ovulation, the second sample was collected at a median of 0 days (range $0-2$ days) from the positive LH-test. The third sample (mid-luteal phase) was collected at a median of 7 days (range 6-9 days) after the positive LHtest and the fourth sample at a median of 2 days (range 1-3 days) before the next menstruation. Figure 1 presents the sample times in relation to the normal changes in estradiol, progesterone and LH during the menstruation cycle. The estradiol and progesterone serum levels were assessed at each sampling occasion to verify the phase of the ovulatory cycle. The women on OCs (control women) were sampled twice during the anticonception cycle. The first sample was collected during the interlude of the anticonception cycle (after a median of 5 days without OCs, range 2-6 days). The second sample was collected during the period with OCs (after a median of 18 days with OCs, range 16-19 days). The men were sampled once at a random time point. 
Blood was collected in a 3.0-mL $\mathrm{K}_{2} \mathrm{E}$ Venosafe EDTA tube for analysis of haematology variables, in a 3.0-mL Hirudin tube for impedance aggregometry and in a 3.5-mL serum tube containing coagulation factors (BD Vacutainer; Becton Dickinson and Company, Franklin Lakes, NJ, USA) for analysis of the hormone levels. For the test and control women, heavy menstrual bleeding and number of days with sanitary protection during the menstruation were recorded.

\section{Haematology variables and hormone levels}

Platelet concentration and haematocrit (Hct) were determined in the EDTA sample using a haematology analyzer (Cell-Dyn Sapphire, Abbott Diagnostics Division, Abbot Park, IL, USA) according to the accredited methods at the Department of Clinical Chemistry at the University Hospital in Linköping.

The blood sample in the serum tube was allowed to coagulate for at least $30 \mathrm{~min}$, followed by centrifugation at $1800 \mathrm{xg}$ for $10 \mathrm{~min}$. The serum was aliquoted and stored at $-80^{\circ} \mathrm{C}$ until analysis. Estradiol, progesterone and testosterone were analysed with Cobas e 602 (Roche Diagnostics Scandinavia AB, Bromma, Sweden) according to accredited methods at the Department of Clinical Chemistry.

\section{Impedance aggregometry}

Platelets aggregation was assessed by impedance technology using Multiplate (Roche Diagnostics). Multiplate measures platelets adhesion to the electrodes in the test cuvette after stimulation of the platelets with a platelets agonist. The adhesion of the platelets to the electrodes changes the electric resistance between the electrodes which is detected. The aggregation response is followed for $6 \mathrm{~min}$ and the area under the curve (AUC) is determined and used as a measure of aggregation [21]. 
For the analysis, $300 \mu \mathrm{L}$ of pre-warmed $9 \mathrm{mg} / \mathrm{mL} \mathrm{NaCl}$ (B.Braun, Melsungen, Germany) was added to the test cuvette, followed by $300 \mu \mathrm{L}$ of hirudin anticoagulated blood. The blood and buffer were incubated under constant stirring for $3 \mathrm{~min}$. This was followed by the addition of $20 \mu \mathrm{L}$ of a platelets agonist (ADPtest, COLtest, or TRAPtest; Roche Diagnostics). In Part 2, blood was also analysed without the addition of agonist (i.e. using $20 \mu \mathrm{L}$ of $9 \mathrm{mg} / \mathrm{mL} \mathrm{NaCl}$ instead of any agonist) to assess spontaneous aggregation. Analysis of the spontaneous aggregation made it possible to specifically investigate to what extent the response following agonist stimulation was actually induced by the agonist. The final concentrations of the agonists were $32 \mu \mathrm{M}$ for TRAPtest, $6.5 \mu \mathrm{M}$ for ADPtest, and $3.2 \mu \mathrm{g} / \mathrm{mL}$ for COLtest. The aggregation response was followed for 6 min at $37^{\circ} \mathrm{C}$ under constant stirring.

\section{Statistics}

Results are presented as median and $25^{\text {th }}$ to $75^{\text {th }}$ percentiles. Statistical comparisons were made using IBM SPSS Statistics version 22.

\section{Part 1}

Comparisons between the different age groups were made separately for women and men with the Kruskall-Wallis test and applying Mann-Whitney U test to determine which agegroups differed and Bonferroni post-hoc test to adjust for multiple comparisons. MannWhitney $U$ test was used for comparison between men and women of the same age group. In a separate analysis a comparison was made between men of all age groups (i.e. age 20-65), menstruating women (i.e. age 20-45), and postmenopausal women (i.e. age 60-65) as well as between these two female groups using Kruskall-Wallis test and applying Mann-Whitney U 
test to determine which groups differed. Bonferroni post-hoc was used to adjust for multiple comparisons.

\section{Part 2}

Friedman's test was used for comparisons between the sample times of the women in the test group and Wilcoxon signed rank test was applied to determine which sample times differed using a Bonferroni post-hoc test to adjust for multiple comparisons. For comparisons between the sampling times for the control women Wilcoxon's signed rank test was used.

Comparisons between control women and test women were made between sample 1 for control women and sample 1 for the test women as well as between sample 2 for control women and sample 3 for test women using Mann-Whitney U-test. A mean was calculated for all sampling times for each individual woman and used for the comparison with the men applying the Mann-Whitney U test. 


\section{Results}

\section{Part 1}

There was no difference in platelet count between the groups (Table I). Hct was significantly higher in men than in women of the same age group (Table I). Hct was higher in women of older age but remained unchanged in the men.

Women in the age group of 20-25 years had significantly higher agonist-induced aggregation than women in the age group of 60-65 but there were no difference between the men of the different age groups (Table I). The women of the younger age groups (20-25 and 40-45 years) also had significantly higher aggregation response than the men but there was no difference between men and women in the oldest age group (60-65 years). A separate comparison between men of all age groups (age 20-65), fertile women (age 20-45), and postmenopausal women (age 60-65) showed that men and older women had significantly lower agonist-induced aggregation response than the younger women (Table II).

\section{Part 2}

The test women without OCs had a low estradiol level at the first sample time but had a significant ovulatory phase increase. This was followed by a gradual decrease throughout the rest of the menstrual cycle (Table III). All women had a progesterone level above the lower reference limit for luteal phase $(>13 \mathrm{mmol} / \mathrm{L})$ at the third sampling occasion verifying that a corpus luteum had developed and that ovulation had occurred prior to this sample occasion. This was also the time when the highest progesterone levels were found. Testosterone was low but significantly higher at the second (ovulatory) sample and was highest for 16 of the 17 women at this ovulatory sample time. 
There were no changes in aggregation response throughout the menstrual cycle with exception of spontaneous aggregation which was lowest at the third sampling time (Table III). Women on OCs had no difference in aggregation response between the period with OCs (sample 2) and the tablet-free week (sample 1).

Hct was shown to be slightly different between the groups with men having significantly higher Hct than both control and test women (Table IV). The women on OCs had the highest platelet count, significantly higher than for both men and women without OCs. However, their spontaneous aggregation was shown to be lower than for both these groups (Table III and IV). Women on and without OCs also had higher aggregation response than men but for some agonists it was only significant after having adjusted for the spontaneous response (Table IV). No difference was seen in the agonist-induced aggregation response between the two groups of women, i.e. women with or without OCs (Table IV).

Eight women in the test group, but none in the OC group, reported that they experienced heavy menstrual bleeding. The median number of days with sanitary protection was 6 [5-6] for the test women and 5 [5-6] for the women on OCs. 


\section{Discussion}

In Part 1 of this study we found that the older women (60-65 years) had significantly lower aggregation response than the youngest women (20-25 years). In contrast, there was no difference between age groups in males. Previous studies have reported conflicting results on the association between age and platelets aggregation [8-10]. It is possible that discrepancies between studies regarding the effect of age on platelet function could be due to the fact that in some studies men and women were analysed in separate groups $[8,13,22]$, in another study men and women as one group [9] whereas in still another study only men were included [10]. This is supported by the fact that we found that younger women had significantly higher aggregation response than men of the same age whereas we found no difference between men and women in the 60-65 year age group. Part 2 of our study confirmed the results of Part 1 regarding a lower aggregation response of platelets from younger men compared with younger women. Our hypothesis is that the higher reactivity of platelets in younger women as compared with men and older, post-menopausal women is a way to prevent excessive blood loss during menstruation.

Others have also reported higher platelet aggregation in younger women than in men as analysed with LTA and Multiplate $[14,19,20]$. Testosterone has been shown to reduce agonist-induced aggregation [14] which might explain the lower aggregation response found in men than in younger women, even though it did not seem to have impact on the spontaneous aggregation. However, in other studies no sex-related difference in aggregation response was found with the two methods $[15,18]$. Furthermore, Meade et al., in contrast to our study, detected higher aggregation in both young and post-menopausal women compared to men of similar age [8]. Differences between studies can be due to different methods to assess aggregation (i.e. LTA vs. impedance technique), variations in agonist concentrations 
$[10,22]$ and analysed aggregation variable (level of aggregation or the concentration of agonist needed to induce a specific level of aggregation) as well as various age groups used in the studies. Kasjanova et al. [10] reported that older age was associated with an increase in aggregation but only when low dose of agonist was used. Furthermore, LTA is also affected by pre-analytical factors including sample collection and preparation [16] and the separation of PRP from whole blood can result in loss of platelets with higher density which could affect the results.

The platelet count and Hct in the different groups in Part 1 were within the age and sex based ranges established by our laboratory and similar to what has been published [23-25]. Both Part 1 and 2 of our study showed that men had significantly higher Hct than women of all ages which is consistent with the literature $[23,24]$. The lower Hct found in women of fertile age is likely due to regular blood loss through menstruations. However, the small differences in Hct found in our study are unlikely to have had any impact on aggregation since others have shown that Hct does not affect platelet aggregation when assessed by Multiplate [20, 2628].

Women on OCs were shown to have higher platelet count than men and women without OCs. Aggregation response with Multiplate has been shown to be affected by platelet count [29-31] with increase in aggregation with increasing number of platelets. The small differences found in platelet count between the groups in this study most likely did not affect the results since the platelet counts in all groups were within the normal range. At this level there is no or only weak association between platelet count and aggregation $[18,27,29]$ and aggregation is believed to be dependent only on platelet function [29]. 
Furthermore, despite the higher platelet count, the women on OCs had lower spontaneous aggregation response than both the men and the women without OCs. During the anticonception period, the women are subjected to high levels of progestogen and estrogen which might have caused the lower spontaneous aggregation since both substances have been shown to inhibit aggregation $[14,32,33]$. However, use of OCs did not affect the agonistinduced aggregation which is in line with the results by Yee et al. who did not detect any effect OCs on agonist-induced aggregation when assessed by LTA [34]. It may be that the few days without use of OCs during the tablet-free week do not result in a high number of new platelets with low exposition to sex steroids to appear in the circulation.

The agonist-induced aggregation response was not significantly altered by changes in the level of estradiol, progesterone or testosterone during the menstruation cycle. This result is in line with previous studies investigating agonist-induced changes during the menstrual cycle with LTA $[34,35]$. Using Multiplate differences in aggregation response during the menstrual cycle were detected only when analysing changes as percentage of day 1 with lowest aggregation in mid-luteal phase [19]. As in our study no difference was found using absolute aggregation values during the cycle and the results varied depending on the type of agonist used [19]. In contrast Teran et al. found that platelets were less reactive in the pre-ovulatory phase than in the mid-luteal phase analysed with LTA and they also found that the result depended on the agonist [36]. We found a decrease in spontaneous aggregation during the cycle with lowest aggregation at the mid luteal phase, a time point associated with high levels of progesterone since one week and high estradiol since three weeks. The results in our study suggest that estradiol and progesterone may affect spontaneous aggregation, a variable rarely studied when assessing aggregation. Spontaneous aggregation has been suggested to be caused by ADP released from the red blood cells [37]. Whether the possible effect of estradiol 
and progesterone on spontaneous platelet aggregation is caused by direct actions on the platelets or by hormonal inhibition of ADP release from red blood cells needs to be further studied.

A limitation in our study is that Part 1 is a small in vitro study with ten individuals in each age and sex group and that we did not register the use of OCs or postmenopausal hormone replacement therapy. It is a strength that the women without anticonception in Part 2 were all shown to ovulate (according to LH-peak measurements and high progesterone in the midluteal phase). This is also confirmed by the highest testosterone levels in the ovulatory phase, which is in line with previous findings of a mid-cycle testosterone peak [38].

The clinical importance of a higher platelet aggregation found in women of fertile age than in postmenopausal women and men, is possibly a mechanism to prevent heavy menstrual bleedings. However, platelet function does not seem to change rapidly enough to be detected throughout the menstrual cycle with its changes in sex steroid levels or from use of oral OCs to the tablet-free week.

\section{Acknowledgement}

We thank our collaborators at the Department of Clinical Chemistry and Clinical Immunology and Transfusion Medicine at Linköping University Hospital for their assistance in the study.

\section{Declaration of Interest}

This study was supported by the grants from Region Östergötland. The authors report no other declarations of interest. 


\section{References}

1. Gorton HJ, Warren ER, Simpson NA, Lyons GR, Columb MO. Thromboelastography identifies sex-related differences in coagulation. Anesth Analg 2000;91:1279-1281.

2. Tynngård N, Lindahl TL, Ramstrom S, Raf T, Rugarn O, Berlin G. Free oscillation rheometry detects changes in clot properties in pregnancy and thrombocytopenia. Platelets 2008;19:373-378.

3. Fritz MA, Speroff L. Clinical Gynecologic Endocrinology and Infertility. 8th ed. Lippincott Williams \& Wilkins, Philadelphia; 2010.

4. Horstman AM, Dillon EL, Urban RJ, Sheffield-Moore M. The role of androgens and estrogens on healthy aging and longevity. J Gerontol A Biol Sci Med Sci 2012;67:1140-1152.

5. Nealen ML, Vijayan KV, Bolton E, Bray PF. Human platelets contain a glycosylated estrogen receptor beta. Circ Res 2001;88:438-442.

6. Jayachandran M, Miller VM. Human platelets contain estrogen receptor alpha, caveolin-1 and estrogen receptor associated proteins. Platelets 2003;14:75-81.

7. Moro L, Reineri S, Piranda D, Pietrapiana D, Lova P, Bertoni A, Graziani A, Defilippi P, Canobbio I, Torti M, et al. Nongenomic effects of 17beta-estradiol in human platelets: potentiation of thrombin-induced aggregation through estrogen receptor beta and Src kinase. Blood 2005;105:115-121.

8. Meade TW, Vickers MV, Thompson SG, Stirling Y, Haines AP, Miller GJ. Epidemiological characteristics of platelet aggregability. Br Med J (Clin Res Ed) $1985 ; 290: 428-432$.

9. Reilly IA, FitzGerald GA. Eicosenoid biosynthesis and platelet function with advancing age. Thromb Res 1986;41:545-554. 
10. Kasjanovova D, Balaz V. Age-related changes in human platelet function in vitro. Mech Ageing Dev 1986;37:175-182.

11. Gleerup G, Winther K. The effect of ageing on human platelet sensitivity to serotonin. Eur J Clin Invest 1988; 18:504-506.

12. Jones CI, Garner SF, Angenent W, Bernard A, Berzuini C, Burns P, Farndale RW, Hogwood J, Rankin A, Stephens JC, et al. Mapping the platelet profile for functional genomic studies and demonstration of the effect size of the GP6 locus. J Thromb Haemost 2007;5:1756-1765.

13. Vilen L, Jacobsson S, Wadenvik H, Kutti J. ADP-induced platelet aggregation as a function of age in healthy humans. Thromb Haemost 1989;61:490-492.

14. Haque SF, Matsubayashi H, Izumi S, Sugi T, Arai T, Kondo A, Makino T. Sex difference in platelet aggregation detected by new aggregometry using light scattering. Endocr J 2001;48:33-41.

15. Beyan C, Kaptan K, Ifran A, Savasci S, Ozturk Y, Okmen B. Effect of sex difference on platelet aggregation using an optical method in healthy subjects. Clin Lab Haematol 2006;28:14-16.

16. Israels SJ. Laboratory testing for platelet function disorders. Int J Lab Hematol 2015;37 Suppl 1:18-24.

17. Tynngard N, Lindahl TL, Ramstrom S. Assays of different aspects of haemostasis what do they measure? Thromb J 2015;13:8.

18. Seyfert UT, Haubelt H, Vogt A, Hellstern P. Variables influencing Multiplate(TM) whole blood impedance platelet aggregometry and turbidimetric platelet aggregation in healthy individuals. Platelets 2007;18:199-206. 
19. Melamed N, Yogev Y, Bouganim T, Altman E, Calatzis A, Glezerman M. The effect of menstrual cycle on platelet aggregation in reproductive-age women. Platelets 2010;21:343-347.

20. Rubak P, Villadsen K, Hvas AM. Reference intervals for platelet aggregation assessed by multiple electrode platelet aggregometry. Thromb Res 2012;130:420-423.

21. Johnston LR, Larsen PD, La Flamme AC, Harding SA. Methodological considerations for the assessment of ADP induced platelet aggregation using the Multiplate(R) analyser. Platelets 2013;24:303-307.

22. Johnson M, Ramey E, Ramwell PW. Sex and age differences in human platelet aggregation. Nature 1975;253:355-357.

23. Swaanenburg JC, Rutten WP, Holdrinet AC, van Strik R. The determination of reference values for hematologic parameters using results obtained from patient populations. Am J Clin Pathol 1987;88:182-191.

24. Mahlknecht U, Kaiser S. Age-related changes in peripheral blood counts in humans. Exp Ther Med 2010;1:1019-1025.

25. Biino G, Santimone I, Minelli C, Sorice R, Frongia B, Traglia M, Ulivi S, Di Castelnuovo A, Gogele M, Nutile T, et al. Age- and sex-related variations in platelet count in Italy: a proposal of reference ranges based on 40987 subjects' data. PloS one 2013;8:e54289.

26. Bochsen L, Johansson PI, Kristensen AT, Daugaard G, Ostrowski SR. The influence of platelets, plasma and red blood cells on functional haemostatic assays. Blood Coagul Fibrinolysis 2011;22:167-175.

27. Ranucci M, Baryshnikova E, Crapelli GB, Ranucci M, Meloni S, Pistuddi V, Clinical, Surgical Outcome Research Score G. Electric impedance platelet aggregometry in 
cardiac surgery patients: A comparative study of two technologies. Platelets 2016;27:185-190.

28. Danielak D, Komosa A, Tomczak A, Graczyk-Szuster A, Lesiak M, Glowka F, Karazniewicz-Lada M. Determinants of high on-treatment platelet reactivity and agreement between VerifyNow and Multiplate assays. Scand J Clin Lab Invest 2017;77:190-198.

29. Hanke AA, Roberg K, Monaca E, Sellmann T, Weber CF, Rahe-Meyer N, Gorlinger K. Impact of platelet count on results obtained from multiple electrode platelet aggregometry (Multiplate). Eur J Med Res 2010;15:214-219.

30. Kander T, Larsson A, Taune V, Schott U, Tynngard N. Assessment of Haemostasis in Disseminated Intravascular Coagulation by Use of Point-of-Care Assays and Routine Coagulation Tests, in Critically Ill Patients; A Prospective Observational Study. PloS one 2016;11:e151202.

31. Shams Hakimi C, Fagerberg Blixter I, Hansson EC, Hesse C, Wallen H, Jeppsson A. Effects of fibrinogen and platelet supplementation on clot formation and platelet aggregation in blood samples from cardiac surgery patients. Thromb Res 2014;134:895-900.

32. Boudoulas KD, Cooke GE, Roos CM, Bray PF, Goldschmidt-Clermont PJ. The P1A polymorphism of glycoprotein IIIa functions as a modifier for the effect of estrogen on platelet aggregation. Arch Pathol Lab Med 2001;125:112-115.

33. Bar J, Lahav J, Hod M, Ben-Rafael Z, Weinberger I, Brosens J. Regulation of Platelet Aggregation and Adenosine Triphosphate Release In Vitro by 17 b-Estradiol and Medroxyprogesterone Acetate in Postmenopausal Women. Thromb Haemost 2000;84:695-700. 
34. Yee DL, Sun CW, Bergeron AL, Dong JF, Bray PF. Aggregometry detects platelet hyperreactivity in healthy individuals. Blood 2005;106:2723-2729.

35. Theodorou AE, Mistry H, Davies SL, Yamaguchi Y, Horton RW. Platelet alpha 2adrenoceptor binding and function during the menstrual cycle. J Psychiatr Res 1987;21:163-169.

36. Teran E, Escudero C, Vivero S. Physiological changes in platelet aggregation and nitric oxide levels during menstrual cycle in healthy women. Nitric Oxide 2002;7:217220.

37. Bampalis VG, Brantl SA, Siess W. Why and how to eliminate spontaneous platelet aggregation in blood measured by multiple electrode aggregometry. J Thromb Haemost 2012;10:1710-1714.

38. Bui HN, Sluss PM, Blincko S, Knol DL, Blankenstein MA, Heijboer AC. Dynamics of serum testosterone during the menstrual cycle evaluated by daily measurements with an ID-LC-MS/MS method and a 2nd generation automated immunoassay. Steroids 2013;78:96-101. 
Figure 1. Changes in sex-hormones estradiol, progesterone and luteinizing hormone (LH) over the course of the menstrual cycle. Sample times for the women without oral contraceptives are indicated. 


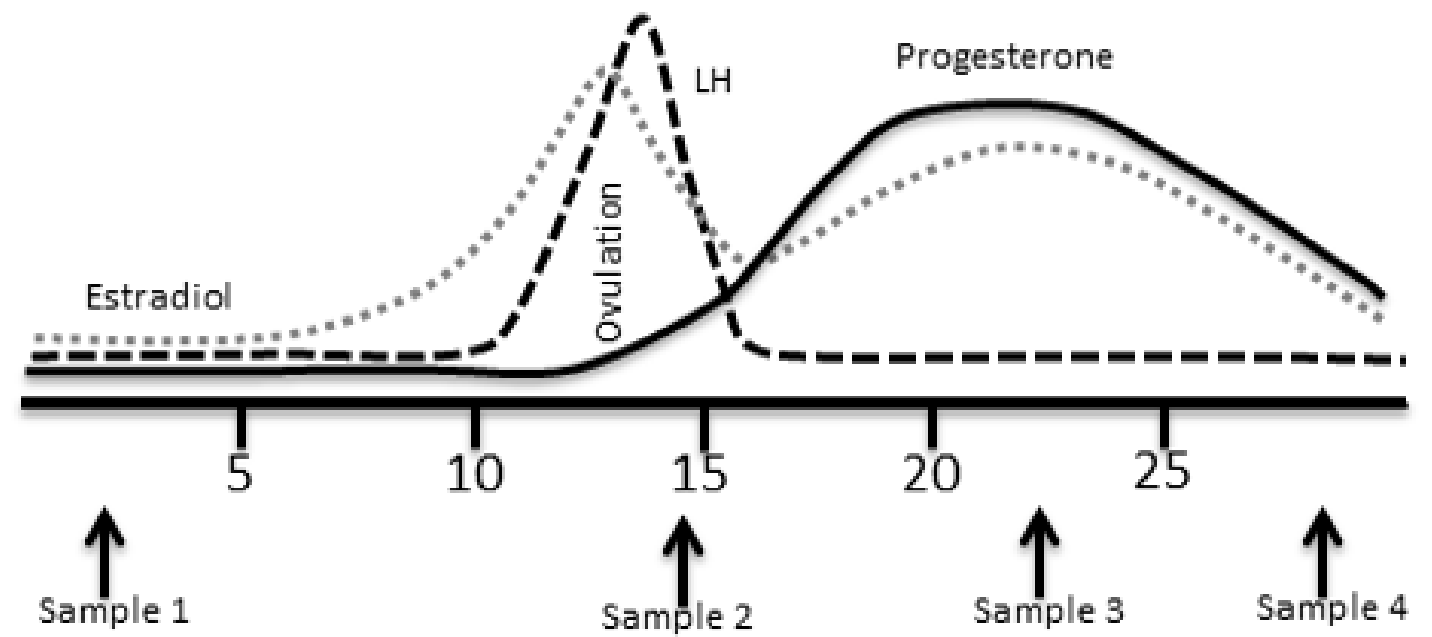

Day of menstruation cycle 
Table I. Part 1: Haematology variables and aggregation response of men and women of different age groups.

$\begin{array}{lllllll} & \text { Women 20-25 } & \text { Women 40-45 } & \text { Women 60-65 } & \text { Men 20-25 } & \text { Men 40-45 } & \text { Men 60-65 } \\ & (\mathrm{n}=10) & (\mathrm{n}=10) & (\mathrm{n}=10) & (\mathrm{n}=10) & (\mathrm{n}=10) & (\mathrm{n}=10) \\ \text { Platelet count }\left(\mathrm{x} 10^{9} / \mathrm{L}\right) & 266[240-297] & 277[225-325] & 296[260-301] & 237[229-282] & 230[204-255)] & 241[233-269] \\ \text { Haematocrit }(\%) & 39[39-41]^{\mathrm{c}} & 41[40-42] & 43[42-43]^{\mathrm{a}} & 45(44-46]^{\mathrm{a}} & 46[45-47]^{\mathrm{b}} & 44[43-46]^{\mathrm{c}} \\ \text { Aggregation response } & & & & & & \\ \text { ADP-AUC (AU x min) } & 832[752-887]^{\mathrm{c}} & 847[781-1079] & 679[581-743)^{\mathrm{a}} & 676[561-779]^{\mathrm{a}} & 679[581-743]^{\mathrm{b}} & 572[499-662] \\ \text { TRAP-AUC (AU x min) } & 1226[1168-1315]^{\mathrm{c}} & 1141[1070-1348] & 993[916-1106]^{\mathrm{a}} & 1048[948-1115]^{\mathrm{a}} & 993[916-1106] & 995[843-1070] \\ \text { COL-AUC (AU x min) } & 914[801-951] & 795[755-988] & 707[612-790] & 734[679-840]^{\mathrm{a}} & 666[621-758]^{\mathrm{b}} & 630[556-757]\end{array}$

Results are presented as median and the $25^{\text {th }}$ and $75^{\text {th }}$ percentiles. Statistical comparisons were made between men and women of the same age group as well as between the age groups for women and men separately with ${ }^{\mathrm{a}}=p<0.05$ vs. women $20-25,{ }^{\mathrm{b}}=p<0.05$ vs. women $40-45$ and ${ }^{\mathrm{c}}=$ $p<0.05$ vs. women $60-65$. 
Table II. Part 1: Haematology variables and aggregation response for combined age groups of men and women.

$\begin{array}{llll} & \text { Women 20-45 } & \text { Women 60-65 } & \text { Men 20-65 } \\ & (\mathrm{n}=20) & (\mathrm{n}=10) & (\mathrm{n}=30) \\ \text { Platelet count }\left(\mathrm{x} 10^{9} / \mathrm{L}\right) & 272[233-307] & 296[260-301] & 237[223-272] \\ \text { Haematocrit }(\%) & 40[39-42]^{\mathrm{b}} & 43[42-43]^{\mathrm{a}} & 45[44-47]^{\mathrm{ab}} \\ \text { Aggregation response } & & & \\ \text { ADP-AUC (AU x min) } & 816[750-903]^{\mathrm{b}} & 679[581-743]^{\mathrm{a}} & 619[510-729]^{\mathrm{a}} \\ \text { TRAP-AUC (AU x min) } & 1205[1107-1328]^{\mathrm{b}} & 993[916-1106]^{\mathrm{a}} & 1010[911-1126]^{\mathrm{a}} \\ \text { COL-AUC (AU x min) } & 888[789-1003]^{\mathrm{b}} & 707[612-790]^{\mathrm{a}} & 698[603-817]^{\mathrm{a}}\end{array}$

Results are presented as median and the $25^{\text {th }}$ and $75^{\text {th }}$ percentiles. Statistical significant differences between the groups are shown with ${ }^{\mathrm{a}}=p$ $<0.05$ vs. women $20-45$ and $^{\mathrm{b}}=p<0.05$ vs. women $60-65$. 
Table III. Part 2: Haematology variables, hormone levels and aggregation results of the test women during the menstrual cycle and of control women.

\section{Test women S1 Test women S2 Test women S3 Test women S4 Contr. women S1 Contr. women S2}

\begin{tabular}{|c|c|c|c|c|c|c|}
\hline Day of menstrual cycle & $1[1-2]$ & $15[14-18]$ & $22[21-25]$ & $26[25-29]$ & & \\
\hline Estradiol (pM) & $112[103-138]^{\dagger}$ & $764[356-1265]^{* \dagger}$ & $463[383-577]^{* \dagger}$ & $267[239-344]^{*}$ & n.a & n.a \\
\hline Progesterone (mM) & $2.7[2.2-3.9]^{\dagger}$ & $3.5[2.8-4.8]^{\dagger}$ & $31.0[28.3-40.7]^{* \dagger}$ & $16.1[11.3-17.2]^{*}$ & n.a & n.a \\
\hline Testosterone (nM) & $0.8[0.6-1.0]$ & $1.1[1.0-1.5]^{* \dagger}$ & $0.7[0.6-0.9]$ & $0.8[0.7-0.9]$ & n.a & n.a \\
\hline Platelet count $\left(\times 10^{9} / \mathrm{L}\right)$ & $225[222-248]^{\mathrm{a}}$ & $242[229-259]^{b}$ & $238[212-257]$ & $236[224-258]$ & $292[238-330]^{\mathrm{a}}$ & $286[239-310]^{\mathrm{b}}$ \\
\hline Haematocrit (\%) & $40[37-41]^{\mathrm{a}}$ & $39[38-40]$ & $40[38-41]$ & $39[38-41]$ & $42[40-44]^{\mathrm{a}}$ & $41[41-42]^{*}$ \\
\hline \multicolumn{7}{|c|}{ Aggregation response, $\mathbf{A} \mathbf{U C}(\mathrm{AU} x \mathrm{~min})$} \\
\hline $\mathrm{NaCl}$ & $142[99-221]^{\mathrm{a}}$ & $153[63-223]^{\mathrm{b}}$ & $102[75-134]^{*}$ & $139[116-172]$ & $79[50-130]^{\mathrm{a}}$ & $65[51-96]^{\mathrm{b}}$ \\
\hline ADP & $875[773-915]$ & $819[718-890]$ & $786[729-874]$ & $834[753-906]$ & $851[716-898]$ & $827[759-851]$ \\
\hline TRAP & $1351[1227-1421]$ & 1346 [1194-1415] & $1259[1232-1319]$ & $1213[1175-1310]$ & 1271 [1179-1315] & 1308 [1163-1415] \\
\hline Collagen & 871 [761-927] & 804 [784-855] & 800 [730-839] & 838 [771-871] & 805 [784-969] & 835[799-873] \\
\hline ADP-NaCl & 728 [631-770] & 688 [586-796] & 679 [602-820] & 682 [616-726] & 728 [652-818] & 734 [652-818] \\
\hline
\end{tabular}




\begin{tabular}{|c|c|c|c|c|c|c|}
\hline TRAP-NaCl & 1206 [1019-1316] & 1170 [1015-1295] & 1184 [1071-1220] & 1074 [992-1219] & 1167 [10671252] & 1191 [1091-1348] \\
\hline ollagen- $\mathrm{NaCl}$ & 715 [570-814] & 721 [585-745] & 695 [631-760] & $692[633-720]$ & 738 [633-845] & 771 [701-814] \\
\hline
\end{tabular}

Results are presented as median and the $25^{\text {th }}$ and $75^{\text {th }}$ percentiles within parenthesis ( $\mathrm{n}=17$ for test women i.e. women without oral contraceptives and $\mathrm{n}=19$ for control women i.e. women on oral contraceptives). The test women were sampled in early follicular phase (S1), at the time of ovulation (S2), in mid-luteal phase (S3) and 1-3 days prior the next menstruation (S4). The control women were sampled during the OC free week (S1) and during the OC period (S2). Statistical significant differences between sample times are shown for each group separately with ${ }^{*}=p$ $<0.05$ vs. S1 and ${ }^{\dagger}=p<0.05$ vs. S4. Statistical significant differences are between control women and test women shown with ${ }^{\mathrm{a}}=p<0.05$ for $\mathrm{S} 1$ for test women vs. S1 for control women and ${ }^{\mathrm{b}}=p<0.05$ for $\mathrm{S} 3$ for test women vs. S2 for control women. ADP-NaCl, TRAP-NaCl and Collagen- $\mathrm{NaCl}$ are the agonist-induced response which has been corrected for spontaneous aggregation to $\mathrm{NaCl}$. 
Table IV. Part 2: Comparison of haematology variables and aggregation results of male controls, control women and test women.

$\begin{array}{llll}\text { Variable } & \text { Contr. men } & \text { Contr. women S1-S2 } & \text { Test women S1-S4 } \\ \text { Platelet count }\left(x 10^{9} / \mathrm{L}\right) & 237[227-254] & 289[243-322]^{\mathrm{a}} & 241[220-255] \\ \text { Haematocrit }(\%) & 45[42-47] & 42[39-43]^{\mathrm{a}} & 39[39-41]^{\mathrm{a}} \\ \text { Aggregation response, AUC (AU x min) } & & \\ \mathrm{NaCl} & 161[96-207] & 81[57-99]^{\mathrm{a}} & 148[104-177] \\ \mathrm{ADP} & 750[642-817] & 810[751-878] & 817[754-894] \\ \text { TRAP } & 1188[1008-1292] & 1282[1177-1342] & 1301[1232-1339]^{\mathrm{a}} \\ \text { Collagen } & 717[669-832] & 831[789-910]^{\mathrm{a}} & 820[769-897]^{\mathrm{a}} \\ \text { ADP-NaCl } & 599[494-669] & 731[639-803]^{\mathrm{a}} & 690[627-757]^{\mathrm{a}} \\ \text { TRAP-NaCl } & 1056[832-1157] & 1156[1082-1280]^{\mathrm{a}} & 1142[1054-1262] \\ \text { Collagen- } \mathrm{NaCl} & 612[450-675] & 732[693-828]^{\mathrm{a}} & 711[613-762]^{\mathrm{a}}\end{array}$

Results are presented as median and the $25^{\text {th }}$ and $75^{\text {th }}$ percentiles within parenthesis $(n=18$ for men, $n=17$ for test women i.e. women without oral contraceptives and $n=19$ for control women i.e. women on oral contraceptives). The test women were sampled in early follicular phase (S1), at the time of ovulation (S2), in mid-luteal phase (S3) and 1-3 days prior the next menstruation (S4). The control women were sampled during the 
OC free week (S1) and during the OC period (S2). Statistical differences between control men and control- and test women, respectively are shown with ${ }^{\mathrm{a}}=p<0.05$ vs. control men. The mean results for all sampling times for each control- and test woman were used for the comparison with the control men. ADP-NaCl, TRAP-NaCl and Collagen- $\mathrm{NaCl}$ are the agonist-induced response which has been corrected for spontaneous aggregation to $\mathrm{NaCl}$. 